\title{
Aplikasi Identifikasi Wajah Berbasis Android
}

\author{
I Kadek Surya Widiakumara ${ }^{1}$, I Ketut Gede Darma Putra ${ }^{2}$, Kadek Suar Wibawa ${ }^{3}$ \\ Program Studi Teknologi Informasi, Fakultas Teknik, Universitas Udayana \\ Jl. Raya Kampus Unud, Bukit Jimbaran, Badung, Bali, Indonesia \\ 1surya.slummdog@gmail.com \\ 2ikgdarmaputra@gmail.com \\ ${ }^{3}$ suar_wibawa@yahoo.com
}

\begin{abstract}
Abstrak
Teknologi identifikasi telah banyak dikembangkan saat ini, seperti identifikasi sidik jari, telapak tangan dan wajah. Identifikasi merupakan penentuan atau penetapan identitas seseorang dan proses mengidentifikasi adalah kegiatan dalam menentukan atau menetapkan identitas seseorang. Pengembangan teknologi identifikasi ini telah diterapkan pada macam-macam perangkat salah satunya pada smartphone berbasis Android. Kebanyakan dari pengembangan identifikasi berbasis Android masih menggunakan teknologi peyimpanan pada perangkat itu sendiri. Metode Eigenface digunakan untuk mengekstrak informasi yang relevan dari sebuah citra wajah, kemudian mengubahnya kedalam satu set kode yang paling efisien dan kode tersebut dibandingkan dengan kode dari citra wajah yang telah disimpan pada basis data. Aplikasi Identifikasi Wajah Berbasis Android ini dibangun dengan menggunakan teknologi penyimpanan pada server (MySQL) dan juga menggunakan Meode Eigenface. Tingkat keberhasilan dari uji coba identifikasi wajah sebesar $68 \%$ dan tingkat salah pengenalan sebesar $32 \%$, dari total uji coba sebanyak 25 kali identifikasi. Beberapa faktor penting yang mempengaruhi tingkat keberhasilan identifikasi yaitu posisi wajah dan intensitas cahaya saat melakukan pendaftaran.
\end{abstract}

Kata kunci: Identifikasi, Eigenface, Pengenalan Wajah.

\begin{abstract}
Identification technology has been widely developed today, such as fingerprint identification, palms and face. Identification is the determination of a person's identity and the process of identifying is an activity in determining or establishing a person's identity. Development of this identification technology has been applied to various devices one of them on Android based smartphone. Most of the development of Android based identification is still use storage technology on the device itself. The Eigenface method is used to extract the relevant information from a face image, then convert it into the most efficient set of codes and the code is compared to the code from the properties it has stored in the database. Face Identification Application Android Based is built by using storage technology on the server (MySQL) and also use the Eigenface Method. The success rate of face identification test results was $68 \%$ and the false accept rate of $32 \%$, of the total trial was 25 times identification. Some important factors that influence the success rate of identification are the position of the face and the intensity of light during enrollment.
\end{abstract}

Keywords: Identification, Eigenface, Face Recognition.

\section{Pendahuluan}

Teknologi identifikasi telah banyak dikembangkan saat ini, seperti identifikasi sidik jari, telapak tangan dan wajah. Identifikasi merupakan penentuan atau penetapan identitas seseorang dan proses mengidentifikasi adalah kegiatan dalam menentukan atau menetapkan identitas seseorang. Pengembangan teknologi identifikasi ini telah diterapkan pada macam-macam perangkat salah satunya pada smartphone berbasis Android. 
Penelitian terkait Metode Eigenface yang diimplementasikan untuk pengenalan wajah sudah lebih dulu dilakukan oleh Putu Alan Arismandika dengan penelitian yang berjudul "Face Recognition System On Android Using Eigenface Method" untuk mengetahui keakuratan pengenalan citra wajah menggunakan Metode Eigenface pada platform Android dengan menggunakan penyimpanan basis data SQLite [1].

Penelitian terkait sistem identifikasi yang diimplementasikan oleh Darma Putra dengan judul "High Performance Palmprint Identification System Based on Two Dimensional Garbor" yang bertujuan untuk memperkenalkan metode segmentasi ROI telapak tangan titik pusat moment dua tahap dan menerapkan metode Garbor dua dimensi untuk menghasilkan kode telapak tangan sebagai fitur telapak tangan serta menggunakan metode jarak hamming untuk mengukur tingkat kemiripan dua vektor telapak tangan [2].

Penelitian terkait sistem identifikasi yang diimplementasikan oleh Dwi Rusjayanthi dengan judul "Identifikasi Biometrika Telapak Tangan Menggunakan Metode Pola Busur Terlokalisasi, Block Standar Deviasi, dan K-Means Clustering" melakukan pengujian sistem identifikasi telapak tangan dengan tingkat akurasi mencapai 94\% dengan menggunakan metode ternormalisasi dengan scaling dan koefisien pengali. Proses clustering dengan algoritma k-means menghasilkan tingkat akurasi lebih rendah sebesar 92\%. Penghematan waktu mencapai 45,04\% dengan penerapan k-means untuk clustering pada metode block standar deviasi [3].

Berdasarkan penjelasan diatas, penelitian yang berjudul "Aplikasi Identifikasi Wajah Berbasis Android" diangkat untuk melakukan pengembangan dan menguji teknologi identifikasi wajah pada smartphone bebasis Android dengan menggunakan teknologi penyimpanan pada server (MySQL) dan Metode Eigenface.

\section{Metodologi Penelitian}

Alur penelitian diperlukan sebagai acuan atau kerangka kerja penelitian, sehingga dapat memperoleh suatu keluaran atau hasil yang terkonsep. Alur yang digunakan dalam perancangan aplikasi identifikasi wajah berbasis Android antara lain:

1. Pendefinisian aplikasi yang dibangun.

2. Identifikasi masalah yang terjadi, terkait dengan aplikasi yang dibangun.

3. Menetapkan tujuan dari penelitian aplikasi identifikasi wajah berbasis Android.

4. Pengumpulan data dan studi kepustakaan yang berhubungan dengan pembuatan aplikasi.

5. Melakukan pemodelan aplikasi dengan mengumpulkan dan memahami hal-hal yang dapat terjadi dalam aplikasi.

6. Melakukan perancangan dan pengembangan aplikasi seperti desain basis data sebagai lokasi penyimpanan data dan pembuatan kode program aplikasi.

7. Pengujian aplikasi dan dokumentasi dari hasil pengujian.

8. Pengambilan kesimpulan dari pengujian yang dilakukan.

\subsection{Gambaran Sistem Pendaftaran Sample Eigenface}

Gambaran sistem pendaftaran sample Eigenface ke dalam basis data ditunjukkan pada Gambar 1.

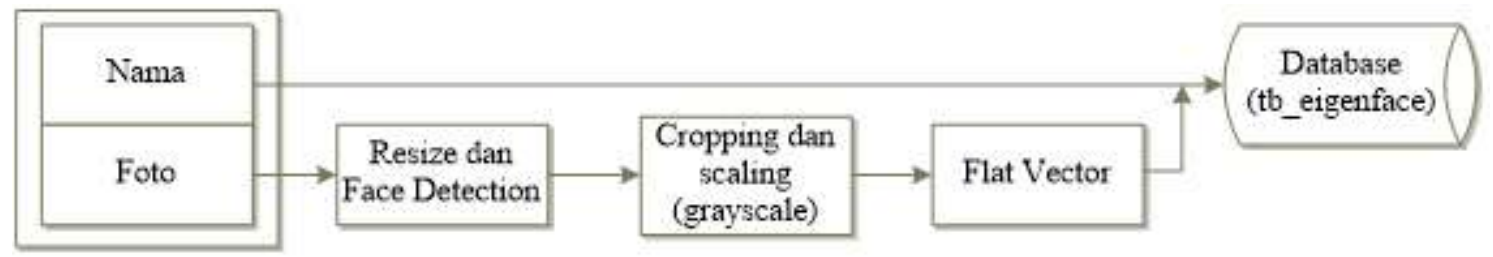

Gambar 1. Gambaran Sistem Pendaftaran Sample Eigenface 
Tahapan-tahapan yang dilakukan pada proses pendaftaran sample Eigenface. Tahap pertama mengisi data nama dan foto. Foto tersebut melewati beberapa proses sebelum seluruh data disimpan ke database. Proses pertama mengubah ukuran foto dan dilakukan deteksi wajah, ketika wajah pada foto terdeteksi dilanjutkan dengan proses cropping. Hasil cropping citra dikonversi menjadi citra grayscale, proses terakhir citra grayscale diubah menjadi flat vector atau array satu dimensi. Sample Eigenface diambil sebanyak 10 data citra wajah diluar dari user yang melakukan pengujian.

\subsection{Gambaran Sistem Pendaftaran User}

Gambaran sistem pendaftaran data dan citra wajah user ke dalam basis data ditunjukkan pada Gambar 2.

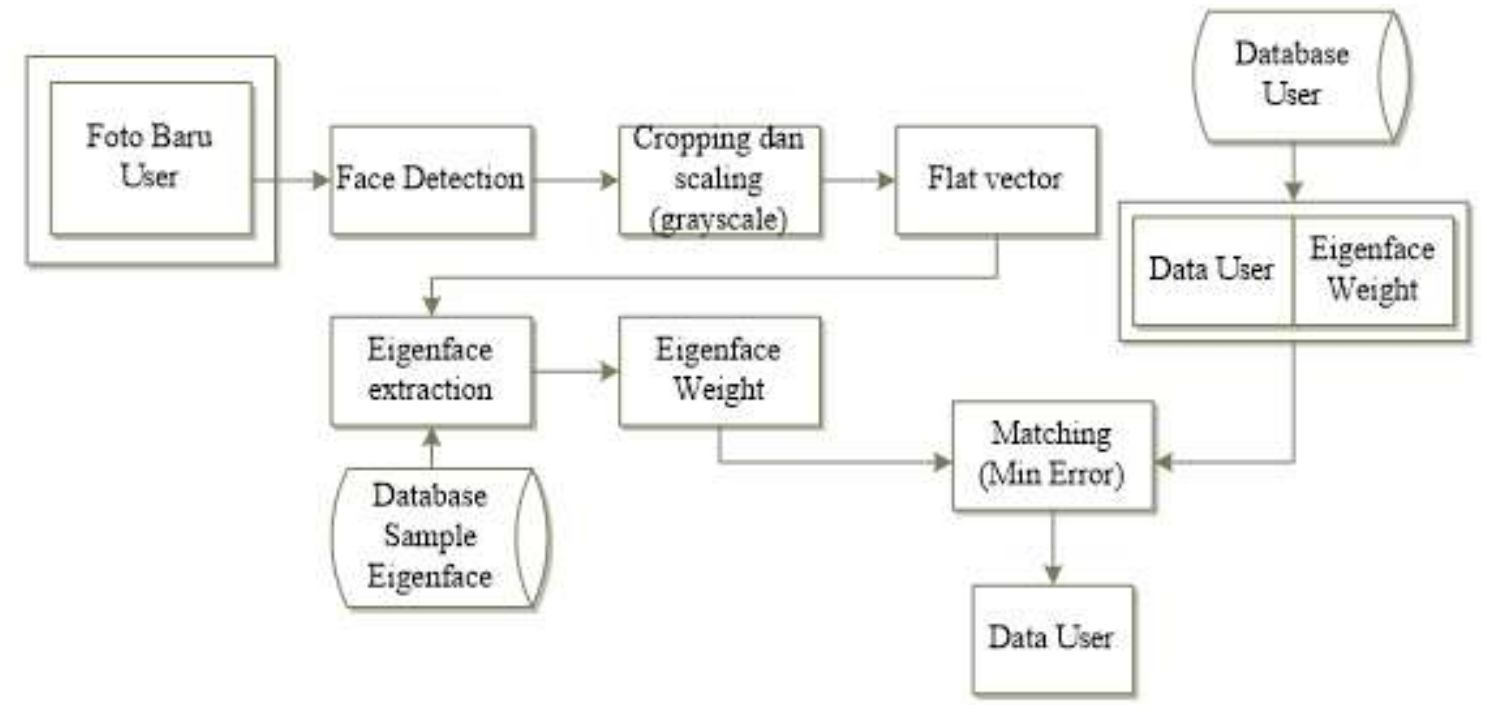

Gambar 2. Gambaran Sistem Pendaftaran User

Tahapan-tahapan yang dilakukan pada proses pendaftaran data dan citra wajah user. Tahap pertama mengisi data user dan foto. Foto tersebut melewati beberapa proses seperti yang dilakukan sebelumnya pada pendaftaran sample Eigenface. Tahap selanjutnya dilakukan Eigenface extraction untuk mendapatkan Eigenface weight atau nilai bobot dari citra. Data user disimpan bersamaan dengan Eigenface weight ke dalam database.

\subsection{Gambaran Sistem Identifikasi}

Gambaran sistem identifikasi citra wajah user yang tersimpan pada basis data ditunjukkan pada Gambar 3. 


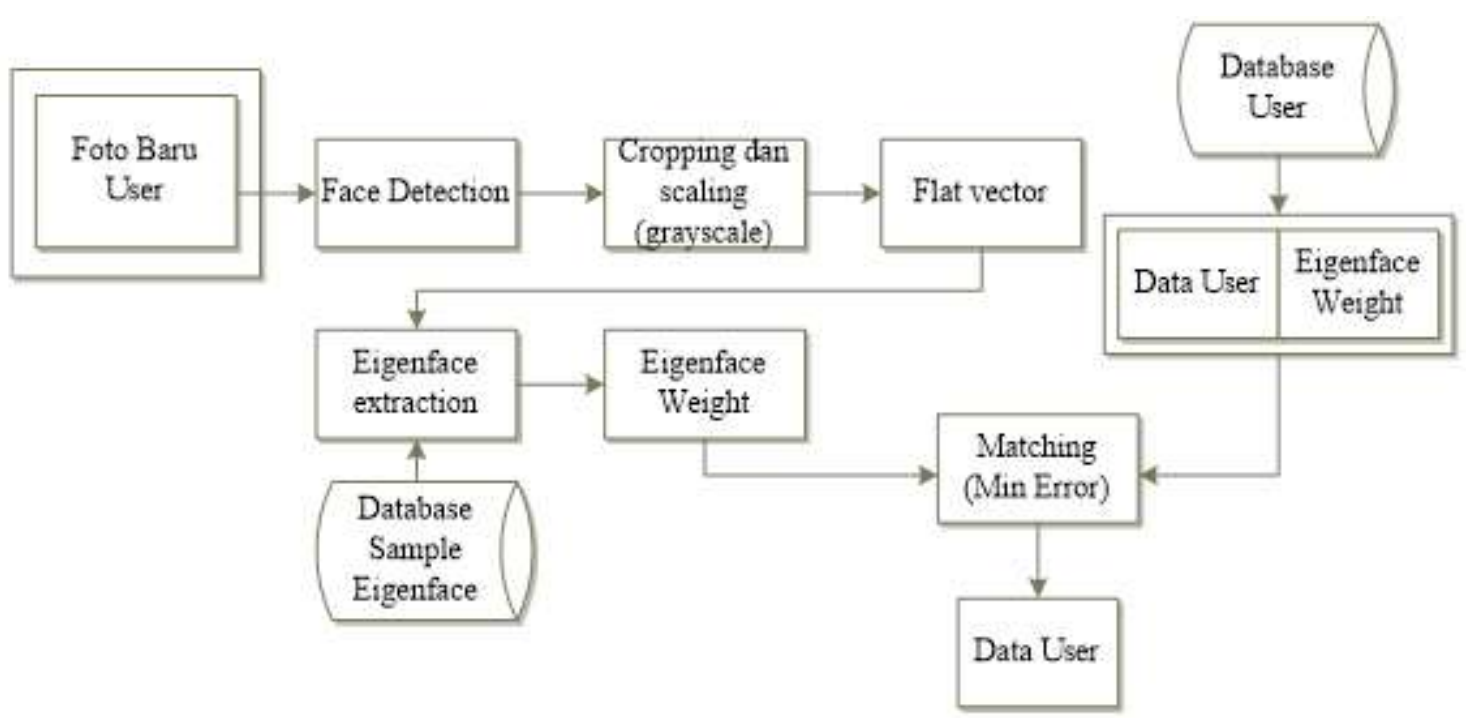

Gambar 3. Gambaran Sistem Identifikasi

Tahapan-tahapan yang dilakukan pada proses identifikasi citra wajah user. Tahap pertama mengambil foto baru dari user untuk diidentifikasi. Foto tersebut diproses sampai mendapakan Eigenface weight atau nilai bobot citra. Eigenface weight citra baru tersebut dibandingkan dengan Eigenface weight citra yang tersimpan pada database. Hasil identifikasi yang muncul adalah data user yang memiliki jumlah selisih Eigenface weight paling minimum.

\section{Kajian Pustaka}

\subsection{Pengenalan Wajah}

Sebuah wajah mengandung banyak informasi fitur yang dapat dibaca, seperti: mata, hidung dan mulut. Sistem pengenalan wajah adalah sistem yang melakukan metode rekayasa dalam sebuah citra untuk mencari identitas atau informasi yang terkandung pada citra. Sistem pengenalan wajah secara umum dibagi menjadi dua, yaitu deteksi wajah dan pengenalan wajah [1]. Secara umum lokasi mata merupakan titik yang digunakan untuk mengenali wajah [4]. Ada dua cara dalam mengumpulkan data wajah. Pertama dengan akuisisi citra yaitu dengan mendaftarkan wajah secara langsung pada aplikasi dan yang kedua dengan menggunakan database wajah yang ada, sebagai contoh Casia-FaceV5 [5].Teknik yang dapat digunakan untuk mendeteksi wajah dalam sebuah citra, seperti: Geometry-based Methods, Color-based Approaches, Appearance-based Methods, Template Matching Methods.

Faktor yang sering menjadi permasalahan dalam pendeteksian wajah adalah faktor pose, komponen struktural, perputaran gambar, ekspresi wajah, intensitas yang tak wajar, kondisi wajah, kekuatan penerangan cahaya.

\section{2. $\quad$ Eigenface}

Eigenface merupakan cara mengekstrak informasi yang relevan dari sebuah citra wajah lalu diubah ke dalam satu set kode efisien dan kode wajah tersebut dibandingkan dengan basis data wajah yang telah dikodekan secara serupa. Algoritma Eigenface yaitu menentukan Eigenvector pada citra di basis data dan mencocokannya dengan Eigenvalue pada training face [1]. Rumus umum dari Eigenface adalah sebagai berikut:

1. Langkah pertama menyiapkan data dengan membuat suatu himpunan $S$ yang terdiri dari seluruh training Image (citra uji) [6]

$$
\mathrm{S}=\Gamma_{1}, \Gamma_{2}, \ldots ., \Gamma_{\mathrm{M}}
$$

2. Langkah kedua mengambil nilai tengah atau Mean [7] 


$$
\Psi=\frac{1}{M} \sum_{n=1}^{M} \Gamma n
$$

3. Langkah ketiga menghitung nilai matriks kovarian (C)

$$
\begin{aligned}
& \mathrm{C}=\frac{1}{M} \sum_{n=1}^{M} \phi n \phi_{n}^{T}=\mathrm{AA}^{\mathrm{T}} \\
& \text { Dengan: } \\
& \mathrm{A}=\{\phi 1, \phi 2, \phi 3, \ldots, \phi \mathrm{n}\} \\
& \text { Dan: } \\
& \mathrm{L}=\mathrm{A}^{\mathrm{T}} \mathrm{A} \quad \mathrm{L}=\phi n \phi_{n}^{T}
\end{aligned}
$$

4. Langkah keempat menghitung Eigenvalue dan Eigenvector dari matriks kovarian (C)

$$
\text { C. } v_{\mathrm{i}}=\lambda_{\mathrm{i}} \cdot v_{\mathrm{i}}
$$

5. Langkah kelima menghitung Eigenface

$$
\mu 1=\frac{1}{M} \Sigma_{k=1}^{M} \mu_{l k} \phi_{k}
$$

6. Langkah keenam melakukan perhitungan Eigenface untuk mendapatkan nilai Eigenface dari training image

$$
\begin{aligned}
& \mu_{\text {new }}=v .\left(\Gamma_{\text {new }}-\Psi\right) \\
& \Omega=\left[\mu_{1}, \mu_{2}, \ldots, \mu_{n}\right]
\end{aligned}
$$

7. Langkah terakhir menggunakan metode Euclidean Distance untuk mencari jarak terdekat antara Eigenface weight (nilai bobot citra) dari training image baru dengan Eigenface weight pada database (matching) [8]

$$
\varepsilon=\|\Omega-\Omega \mathrm{k}\|
$$

\section{Hasil dan Pembahasan}

Hasil dari aplikasi identifikasi wajah berbasis Android ini didapat dengan melakukan uji coba sistem pendaftaran dan dilanjutkan dengan sistem identifikasi. Pembahasan dilakukan untuk mengetahui faktor apa saja yang berpengaruh terhadap sistem identifikasi.

\subsection{Spesifikasi Perangkat Pengujian}

Kebutuhan perangkat keras yang digunakan sebagai pendukung pengujian aplikasi identifikasi wajah berbasis Android ini adalah perangkat smartphone dengan spesifikasi menggunakan sistem operasi Android minimal pada API level 14 (Android 4.0 Ice Crem Sandwich) dan memiliki fitur kamera

\subsection{Uji Coba Sistem Pendaftaran}

Uji coba aplikasi identifikasi wajah berbasis Android yang digunakan untuk melakukan pendaftaran memiliki skema sebagai berikut: 


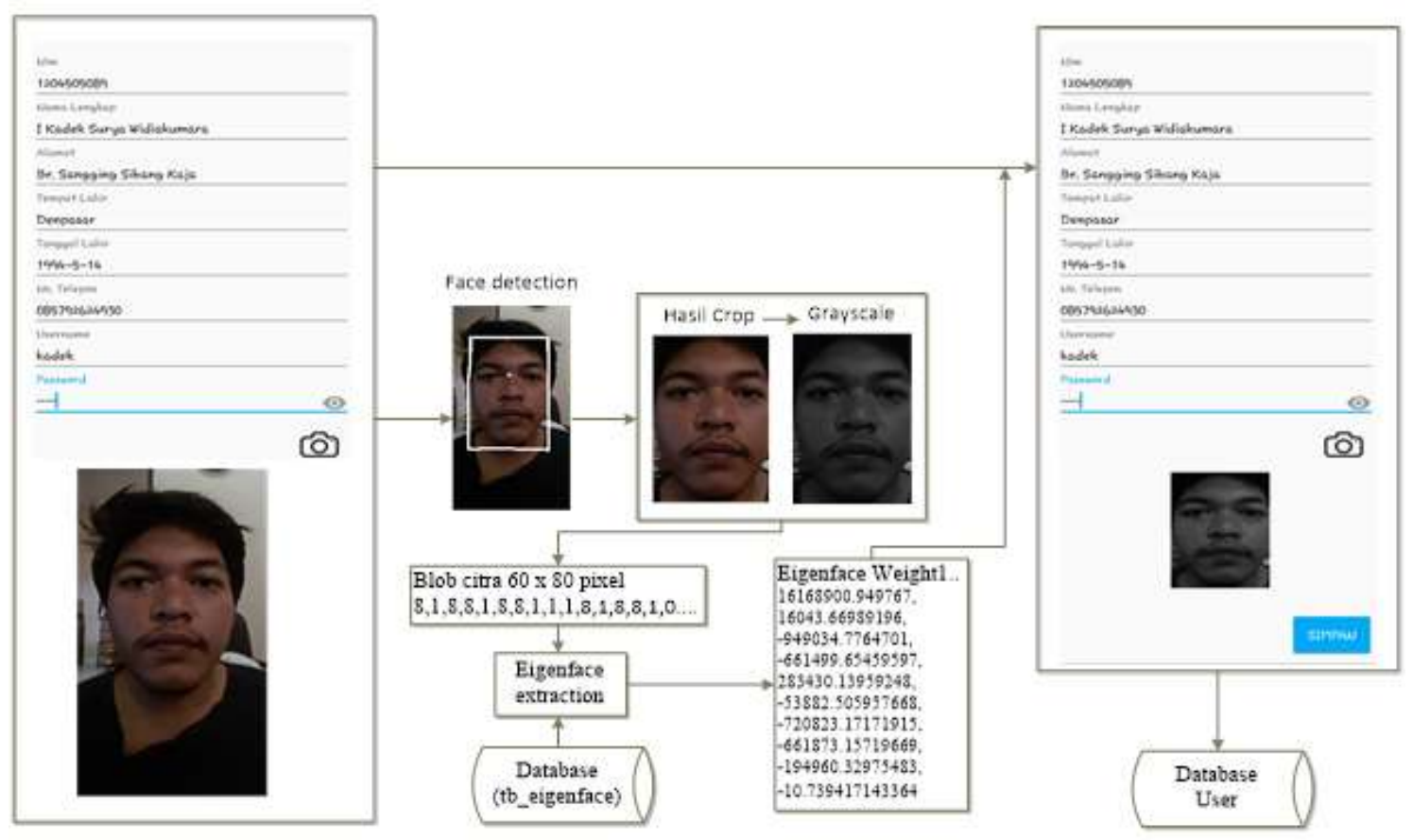

Gambar 4. Skema Sistem Pendaftaran

Pendaftaran dimulai dengan meng-input-kan data lengkap user beserta foto yang bersangkutan. Foto di resize dengan ukuran $134 \times 240$ pixel. Deteksi wajah pada foto yang di resize dilakukan dengan mencari titik tengah wajah, batas kiri, batas kanan, batas atas dan batas bawah. Proses cropping dilakukan dengan kententuan hasil citra berukuran 60x80 pixel. Citra hasil cropping dikonversi menjadi citra grayscale. Citra grayscale diubah menjadi flat vector atau array satu dimensi. Eigenface extraction dilakukan untuk mengekstrak data citra grayscale untuk mendapatkan Eigenface weight atau nilai bobot dari citra. Semua proses telah dilakukan, maka data disimpan menjadi satu antara identitas dengan nilai bobot yang telah didapat kedalam database.

\subsection{Uji Coba Sistem Identifikasi}

Uji coba identifikasi aplikasi absensi deteksi wajah berbasis Android yang digunakan untuk melakukan identifikasi memiliki skema: 


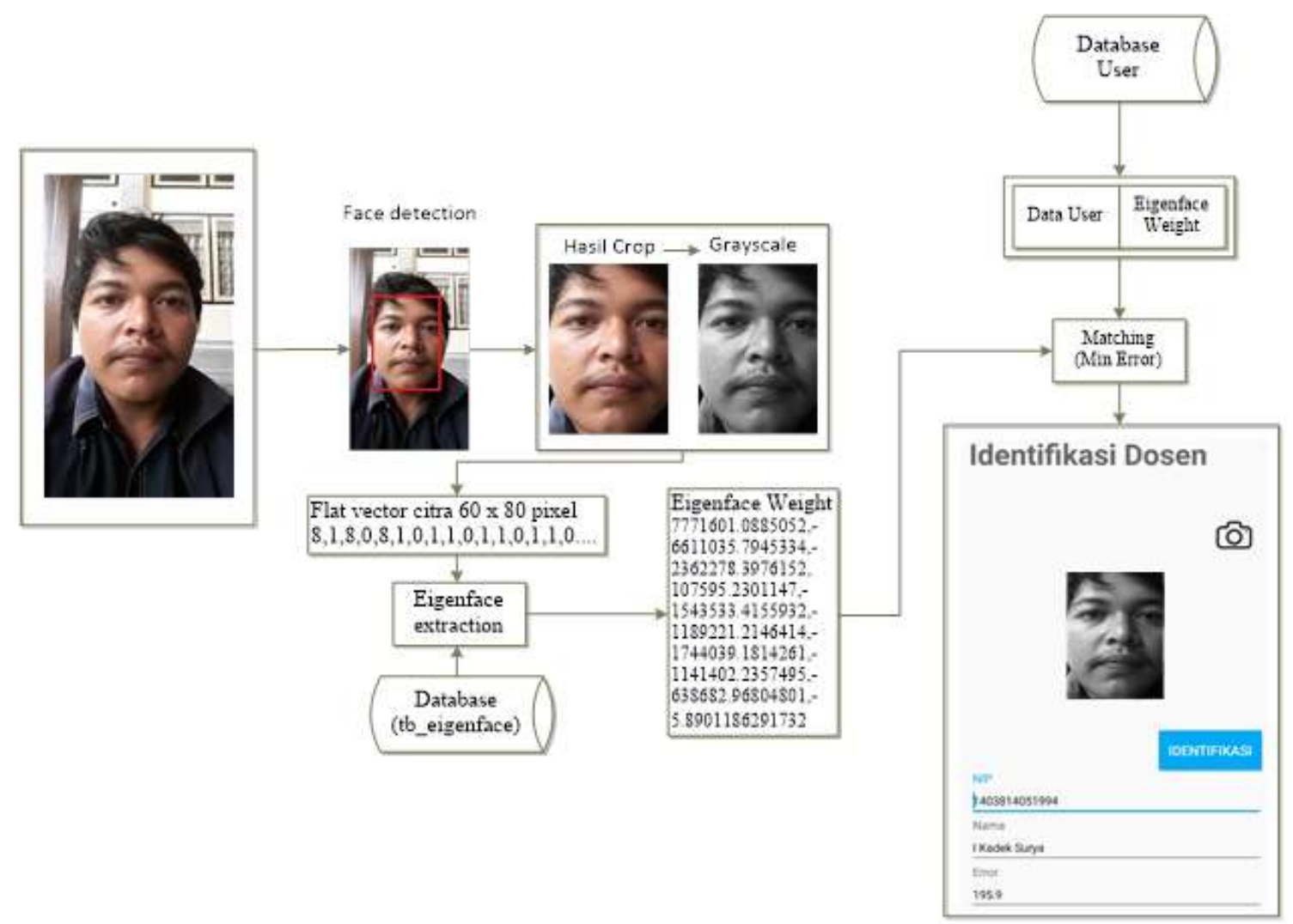

Gambar 5. Skema Sistem Identifikasi

Identifikasi dimulai dengan meng-input-kan foto user yang telah melakukan proses pendaftaran. Foto tersebut melewati beberapa proses seperti pada proses uji coba pendaftaran sampai mendapatkan Eigenface wieght. Tahap selanjutnya membandingkan (matching) Eigenface weight yang baru dengan Eigenface weight yang telah tersimpan pada database. Data yang muncul adalah data user yang memiliki jumlah selisih Eigenface weight terkecil dari semua data yang tersimpan di database.

Uji coba identifikasi menggunakan 5 orang sebagai objek dan dilakukan pengulangan sebanyak 5 kali pada setiap objek. Hasil uji coba dibagi menjadi 2 yaitu tingkat keberhasilan atau success rate (SR) dan tingkat salah pengenalan atau false accept rate (FAR). Tingkat keberhasilan (SR) dilihat dari kesesuaian objek dengan hasil identifikasi, sedangkan tingkat salah pengenalan dilihat dari ketidaksesuaian objek dengan hasil identifikasi. Hasil uji coba identifikasi ditunjukkan pada Tabel 1.

Tabel 1. Hasil Uji Coba Identifikasi

\begin{tabular}{cccc}
\hline Nama User & Banyak Uji Coba & FAR & SR \\
\hline Chatarina & 5 & 0 & 5 \\
Dwiki Chen & 5 & 4 & 1 \\
Poyok & 5 & 0 & 5 \\
Surasmitha & 5 & 0 & 5 \\
Angga Prabawa & 5 & 4 & 1 \\
\hline Total & 25 & 8 & 17 \\
\hline
\end{tabular}

Persentase

Tingkat keberhasilan Success Rate (SR)

Tingkat salah pengenalan False Accept Rate (FAR)

$$
\frac{17}{25} \times 100 \%=68 \%
$$

$$
\frac{8}{25} \times 100 \%=32 \%
$$


Dari total uji coba sebanyak 25 kali identifikasi didapatkan sebanyak 17 kali identifikasi yang benar dan 8 kali identifikasi yang salah mengenali. Dapat disimpulkan persentase dari seluruh uji coba, tingkat keberhasilan identifikasi sebesar $68 \%$ dan tingkat salah pengenalan sebesar $32 \%$. Hasil persentase tingkat keberhasilan dan tingkat salah pengenalan juga dipengaruhi beberapa faktor, seperti posisi wajah dan intensitas cahaya pada saat pendaftaran maupun saat identifikasi citra wajah.

\section{Kesimpulan}

Aplikasi Identifikasi Wajah Berbasis Android dirancang dan dibangun untuk diimplementasikan pada perangkat mobile dengan platform Android. Metode yang digunakan adalah Metode Eigenface. Hasil uji coba identifikasi dari aplikasi ini didapatkan hasil dengan persentase tingkat keberhasilan identifikasi sebesar $68 \%$ dan tingkat salah pengenalan sebesar $32 \%$ dari total uji coba sebanyak 25 kali identifikasi. Hasil persentase tingkat keberhasilan dan tingkat salah pengenalan juga dipengaruhi beberapa faktor, seperti posisi wajah dan intensitas cahaya pada saat pendaftaran maupun saat identifikasi citra wajah. Dilihat dari hasil uji coba aplikasi identifikasi wajah berbasis Android yang telah dilakukan, sistem pendaftaran harus dilakukan dengan mengambil citra wajah dengan berbagai posisi dan tingkat pencahayaan yang berbeda, hal tersebut kiranya dapat meningkatkan persentase tingkat keberhasilan pengenalan dari aplikasi.

\section{Daftar Pustaka}

[1] A. A. K. Oka Sudana, I. K. G. Darma Putra, and A. Arismandika, "Face recognition system on android using Eigenface method," Journal Theoretical Applied Information Technology, vol. 61, no. 1, pp. 128-134, 2014.

[2] I Ketut Gede Darma Putra, "High Performance Palmprint Identification System Based On Two Dimensional Gabor," TELKOMNIKA, vol. 8, no. 1, pp. 309-318, 2010.

[3] Dwi Rusjayanthi, "Deviasi, dan K-Means Clustering," Lontar Komputer: Jurnal Ilmiah Teknologi Informasi, vol. 4, no. 2, pp. 265-276, 2013.

[4] Prof .T Venkat Narayana Rao, D Vishal Reddy, and Rutwik V Jangam, "Face Detection E-Attendence System," International Journal Computer Trends and Technology, vol. 27, no. 3, pp. 152-155, 2015.

[5] IG. P. Fajar Pranadi. Sudhana, "Sampul dan Moment," Lontar Komputer: Jurnal IImiah Teknologi Informasi, vol. 4, no. 2, pp. 277-288, 2013.

[6] Rajesh Kumar Gupta and Umesh Kumar Suhu, "Real Time Face Recognition under Different Conditions," International Journal of Advance Research in Computer Science and Software Engineering, vol. 3, no. 1, pp. 86-93, 2013.

[7] Thuseethan, S. and Kuhanesan, S., "Eigenface Based Recognition of Emotion Variant Faces," The International Institute for Science, Technology and Education, vol. 5, no. 7, pp. 31-38, 2014.

[8] Rajib Saha and Debotosh Bhattacharjee, "Face Recognition Using Eigenfaces," International Journal of Emerging Technology and Advanced Engineering, vol. 3, no. 5, pp. 90-93, 2013. 